mit that women as compared to men are not good losers. Instead of being glad the thing we tried to do has been better done than we could do it, we are sometimes unhappy because it was done by someone else. We still find it hard to applaud the rod work of a rival, we have been known accept special privileges, to expect special indulgences, to stoop to tears or wiles to win our goals. We fail now again in effective team work. We may express this failure in different ways, but the charming woman who told me she had resigned from a committee because Mrs. Very Charming Too had been put on it-"She is a perfectly lovely woman, my dear, and I wouldn't say a word against her for the world. It is just that I am temperamentally unfit to work with her"-meant the same thing as the little girl whom I found refusing to play the game in the gymnasium-"No, I'm not sick, but that pig of a Lillie Wolfe was chosen on my side." Perhaps we older women will never really learn to be good sports but at least we have learned to be ashamed of poor sportsmanship and very tired of the unsportsmanlike ways we have had to work, and we are pinning our faith to this younger generation and are looking forward to watching their good fight and their straight race and their clean game to take the stain of it out of our souls, and the bitterness of it out of our hearts, and the taste of it out of our mouths forever.

\section{VOCATIONAL GUIDANCE IN THE JUNIOR HIGH SCHOOL}

An Address at the Summer Conference of the New England Vocational Guidance Association, Harvard University Summer School, 1922.

\section{LEONARD V. KOOS}

Professor of Secondary Education, University of Minnesota

It is my plan to give in twenty to twenty-five minutes some commonplacesand $I \mathrm{am}$ certain they will seem to you to be commonplaces-bearing on vocational guidance in and through the junior high school. I am going to come right to the point so as to save time.

A. (I) Of course, the junior high school will have to be concerned with guidance as a part of our whole scheme of guidance. As I look at the secondary school period, it is the period extending from the seventh through the fourteenth grade of our school system, a period of eight years for the average child. Looked at from one standpoint, this is the period of guidance. During this period decisions ought to be made with reference to occunational destination, and in other matters where guidance is necessary. What we do through our present typical organizations of the system of education is to cut across this perjod of secondary education, this period of guidance. We cut across it at two points and those points are between the eighth and the ninth grades and between the twelfth and thirteenth, so that we have three units in our school system, or three types of institutions. working at this job of guidance. When you split that job up among three types of institutions that are very different you have three slants on this whole program of guidance, three slants likely to be very different. You break it up into three pieces so that it is not likely to be consistently or coherently done. It is, therefore, my belief that we should have within the secondary school the whole period of guidance, admintstered probably not as a single unit, but at least as a unified period of secondary education throughout which largely the same types of interests will be operative and the same objectives apply.

At the present time we do not have much in the way of guidance in the elementary school. About the only thing of this sort is the visit of the principal of the high school to the elementary school, when he brings his papers, asks the children to select curriculums, and to "sign on the dotted lines." In the four-year high school these children are the recipients of the only real guidance that is available in our system. On account of the organization of the traditional system the problems of guidance have been centered there. The college has of late begun to do a little along guidance lines during the first year, although most of our colleges are leaving guidance as a systematic program alone. In order to have guilance effectively done we need to bring it all together into a single scheme of secondary schools.

(II) What concern is this to the junior high school? This, that the junior high school covers the portion of the period during which the problem of guidance is most acute. The lower portion of this whole new secondary school period, which should to my mind include eight years, is the more important for guidance of the two periods into which our secondary schools of the future are likely to divide, although the obligations, the responsibilities of guidance will also rest very heavily on the senior period above.

I want to have you look for a few minutes at the junior high school and its special purposes to see how hearily the guidance function rests upon that nnit in the system. A good deal of what I say at this point will be repetition to son. You have heard it in classes and elsewhere. But I want to examine briefly a few of those special purposes of the junior high school and then move on to some extent to a brief treatment of the means of achieving or of performing that guidance function. 
One of the first things you find in any complete statement of the distinctive purposes of the junior high school is that it will retain a larger proportion of children than have been retained heretofore. This in itself throws upon us the problem, the obligations, of more guidance than we have been giving in the school years concerned. With a greater variety of students represented in those particular grades we are obliged to provide machinery for directing these children to the various kinds of training for the occupations in which they will participate. Another one of these special purposes that one finds in any complete canvass of the literature is that the junior high school is designed to recognize individual differences. But you cannot recognize Individual differences until you have first found those differences, and a part of the guidance program is ascertaining those differences. Then, of course, we find as another special purpose a very frank and open acknowledgment of the necessity for exploring for guidance in this junior high-school period. Another purpose we might name while dealing with the junior high school is that we must provide the beginnings of vocational education. How can we decide which of these beginnings is to be taken by a particular child without some recognition of our obligations in guidance? Lastly, there is this period of adolescence of which the advocates of junior high school speak. It begins in the neighborhood of the sixth, seventh, and eighth grades,-that is, for most children. One of the interests of adolescence is occupations. Because during this period the child is approaching adulthood, he is approaching adulthood in his interests. His concerns turn more to the occupational than during preadolescence.

(III) With this brief canrass of these speciul purposes I can move now to the third aspect of this whole matter of guidance in the junior high school, preliminary to the brief description of means, the range of guidance requisite. It cannot be restricted to occupational guidance. It will need to be disciplinary guidance and social guidance in the narrower concept of the term. It will need to include educational, vocational, and, of course, recreational guidance. We have been inclined in this country to discredit the recreational interests of children and of the adults. We have failed to recognize training for recreation as a legitimate part of the training of our young people for their present life and for adulthood. Because of this neglect, of course, we have given relatively little concern to guidance in and toward recreational pursuits. We need to provide guidance along that line by providingr types of recreation which these roung people can try out.

We have, thus, in the first place, the
Junior high school as the first unit of our longer period of secondary education, if we accept the junior high school idea. This period of secondary education, from one vital standpoint, constitutes the period of guidance. In the second plac we have a number of special purposes $t$ the junior high school which urge upon us some program of guidance in that unit. And in the third place we have a great variety of life and its interests in which these children need guidance. In consequence, the obligations are there and the question becomes, how to do it. I plan now to give a few suggestions for a plan of activities and procedure that should be included in a program to effect guidance in and through junior high school.

B. (I) In this plan, one of the first things we shall have to think of is the program of studies in its relationship to the whole problem of guidance. This consideration of the program of studies distributes itself under several different heads. The first one concerns the types of programs of study which are in use now. We have several of these. A simple one is the single-curriculum type, which is completely prescribed, $i$. e., the same content is prescribed for all children. There are very few of this type, very few administrators or groups of teachers having the temerity to introduce a strictly singlecurriculum type into the junior high school. Obviously, it provides relatively little opportunity for the performance of the guidance function.

Another type which we designate by the name of the multiple curriculum program may have several curricula, e. g., an academic curriculum, a home economics curriculum, and so forth. Each curricnlum is intended for a particular group of children who are presumed to pursue it usually throughout the three-year period. We have some instances of that pure multiple-curriculum type where all the work is prescribed. If we have three curricula the child starts in the first year of one of these, his work being prescribed throughout the pursuit of that particular curriculum. This procedure obviously cannot satisfy the guidance purposes, because it does not assume that the child should be permitted to shift from one curriculum to another, and it therefore operates to prevent adequate exploration.

We have a third type, the constantswith-variables. In this type, certain materials are required of all children and then throughout the three years of junior high school certain other portions are made rariable. The pupil may shift from one kind of variable to another under proper guidance. He may try himself out, he may be tried out-may explore himself or be explored-hy making contact with a variety of educational material. 
There is a fourth type, a combination of the multiple-curriculum and the constants-with-variables, which I cannot take time to describe, but the nature of which may be judged from what has already teen said. The third and fourth types re the only ones which are feasible in order to provide the possibilities of exploration to any adequate extent. The single-curriculum and the pure multiplecurriculum types do not seem to me to be practicable because they fail to provide the exploration essential during this earlier portion of the secondary school period.

(II) The second aspect of the means of exploration or guidance during the junior high-school period is the materials of instruction. These must be changed definitely from those of the conventional type in order to provide the guidance essential in this period. That is to say, the traditional curricular materials of the seventh, eirhth, and ninth grades as now administered are inadequate for the purposes under consideration. For instance, we need in the constants to insist upon some contact with the field of science. Children need early to be brought in contact with the materials of science for exploratory reasons as well as for their other values. We need to introduce some supra-arithmetical mathematics into the seventh and eighth grades, grades in which it has not traditionally been found. I refer here to elementary parts of algebra and our English needs to be changed in character in order to make the performance of this function of guidance anything like a satisfactory performance. Variables need to be wide in range and character in order to permit the child to explore to some extent the possibilities of the fields represented and also for us as administrators and teachers in junior high schools to explore the child while his own exploration is in process.

(III) As to the industrial arts and their relationship to guidance I want to say a few words. The bench-work in wood and the desultory bits of mechanical drawing which we have in many seventh and eighth grades cannot be regarded as adequate for purposes of exploration. We must provide a wider range of industrial arts for this purpose both in the constant and in the the variable portions of the program of studies. Although it is not the typical situation, there are marked tendencies in the direction of providing a wider range of these curricular contacts.

Here is a little volume by Edgerton, on Industrial Arts in the Junior High School containing some things worth looking at. He indicates here, after having made a questionnaire canvass, the proportion of these schools in communities of sereral sizes that provide a number of different ;kinds of exploratory materials or indus- trial contacts through the junior highschool industrial arts. For example, we find in junior high schools in ninety-six per cent of the cities of 25,000 to 200,000 population six to sixteen types of industrial-activities, which means of course a somewhat greater range and variety than in the traditional type of mechanical drawing and bench-work in wood still all too prevalent in unreorganized schools. Such restricted materials are valuable, of course, but they are inadequate to the wider purposes of exploration. Among other things Edgerton made a canvass by means of his questionnaire of the primary purposes to be held in mind in these industrial arts. According to his returns a proper function of junior high-school industrial arts is "contributing to general experience all round development and industrial intelligence." The second main function of these materials is "aiding in the intelligent selection of industrial occupations without encouraging early choices," The second in importance is thus the purpose of guidance and exploration with which we are here concerned.

Another man, Kenneth V. Carman, has written recently on this subject and reports a study which he made of the valid special purposes of the junior high-school industrial arts. He listed twelve statements of purposes and asked a number of experts in the field to indicate their preferences. He wanted to find out what this large group regarded as the special primary purposes of the industrial arts in the junior high school. "Vocational guidance" value is an important constituent of the statement of purpose held in highest esteem by the persons passing judgment. It is likewise a constituent of each of the two statements of aim stand. ing next highest in the appreciation of this group of judges. There seems therefore to be rather general agreement that one important function of junior high school industrial arts is guidance.

of course, in order to have these industrial arts perform this function we must not restrict the type of activity merely to the tool or manipulative experiences involved. The pupil should also canvass to some extent the wider relationships of each industrial art pursued to other arts, the sources of raw materials used, the services rendered to society, the opportunities of self-realization within each field, including attention to the standard of living attainable, and so forth. The pupil should be brought into contact with the conditions under which the skills being developed are applied in industry, through opportunities for visiting places where the work is going forward and through approximation to the conditions of industry in school shops. The school conditions cannot, and should not in many instances, be just like the 
conditions in industry, but it is desirable to approximate the latler, especially in view of the guidance values and social values to be secured.

I propose to say a word or two about unit courses. There are people in the country who go about telling us, at least by implication, that there can be no funior high school unless there are included in the educational offering these distinct, short-unit courses introduced for the purpose of guidance. I admit that they are likely to be of considerable value. They are not, however, a sine qua non of the junior high school. Proper guidance can be provided through these industrial materials without offering what have come to be designated as shortunit courses. The boys in these shops should not, on the other hand, be restricted to manipulative experiences in bench-work in wood only. We need at least to move in the direction of combination units of work of shorter or longer duration involving two or three types of industrial activity.

(IV) Another one of the means to be used for guidance in the junior high school is the course in vocational civics or vocational information, sometimes referred to as the "life career" course. I should make that course in my junior high school a constant-I should require it of all children. Certainly, should require it of all boys, in the first place, because it is of large socializing value, realized through bringing the child into contact with the work of the world; in the second place, because it puts him in a better position to decide what his line of life work is going to be. I want to give an illustration of the guidance value of such a course. A course of this kind was introduced, partly at my suggestion, into one of the little comunities west of Minneapolis, a small industrial community, largely foreign. It was introduced into the last half of the eighth grade. The group taking it was small. This eighth grade was not in a junior high school but in a system which is moving over to the junior high school reorganization as rapidly as possible, considering local conditions. A group of something like thirty boys and girls took the course referred to. At the opening of the course the pupils were asked whether or not they were going on to high school. In the group there were eirht not planning to go to high school. At the end of the course they asked the same question and all those eight children indicated that they were planning to attend high school. The course had at least shown them the small opportunities of the individual who does not get more extended education.

(V) The extra-curricular activities, rich in guidance ralues, occupational and otherwise, I need only mention, because
I think the educational world in general is recomizing this extra-curricular field as an excellent place for performing this vocational guidance function.

(VI) In any complete program of guidance there must be a scheme of testing. mental, educational, and occupational. shall not enter into discussion of this aspect as Professor Proctor is to deal with it in his presentation this afternoon.

(VII) Lastly, we must have some sort of administrative organization of guidance in the junior high school. I am not certain just what that should be. I am certain of this, however, that the teacher must be regarded as a very important element in the performance of this guidance function and of this advisory organization which we introduce into our jumior high school. The teacher's judgment is and should be the most informative we have. And the teacher should be well equipped for these relationships. The teacher needs to prepare himself for assistance along these lines. He who is a specialist in a subject needs to have the technique of measurement peculiar to that field. A teacher must also be an assistant in the matter of guidance in a more general way through our advisory organization. Every junior high school must come to have this advisory activity on the part of the teacher, and also some sort of head for it. In small junior high schools the work of direction of guidance may best be done by the right kind of princinal. In a lgrger unit it may be necessary $t_{0}$ provide a separate official, for example, a part-time teacher with special training "or the work. In even larger junior high whools full-time persons will be required to head up the guidance work. This work needs to be headed up, it needs to be coordinated. You cannot have eversone working at guidance in his own way.

These are all the commonplaces that I feel moved to present. It seems to no the items indicated are feasible and necessary of introduction. Let me repeat in comclusion that there is a wide opportunity for guidance in the junior high school and it is especially pertinent as we bring larger and larger proportions of the children of those ages into our junior high-school grades-as we expect to do through reorganization.

\section{BULLETINS OF THE JUNIOR EMPLOYMENT SERVICE}

The Junior Employment Service of the Department of Labor has begun to issue, in mimeographed form, a NEWS IETTER and BULLFTINS on matters of current interest. The first NEWS LETTER is dated September, 1922. It contains accounts of the activities of the Junior Division in various parts of the country; a report of the section meeting on Vocational Guidance of the National Educaf 